\title{
Hypertension and Dental Implants: A Review
}

ISSN: 2578-0379

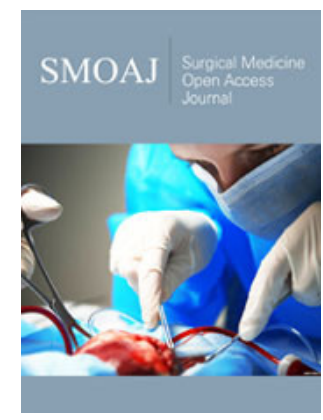

*Corresponding author: Fotoula Nikolopoulou, Assistant professor at Dental School, Greece

Submission: 制 September 28, 2019

Published: 漈October 11, 2019

Volume 3 - Issue 1

How to cite this article: Fotoula Nikolopoulou, Anestis Chrysostomidis. Hypertension and Dental Implants: A Review. Surg Med Open Acc J.3(1). SMOAJ.000554.2019. DOI: 10.31031/SMOAJ.2019.03.000555.

Copyright@ Fotoula Nikolopoulou, This article is distributed under the terms of the Creative Commons Attribution 4.0 International License, which permits unrestricted use and redistribution provided that the original author and source are credited.

\author{
Fotoula Nikolopoulou* and Anestis Chrysostomidis \\ Assistant professor at Dental School, Greece
}

\begin{abstract}
The objectives of this study are to raise some questions in regard to the current literature, in order to study the correlation of hypertension to implant surgery. It also studies the association of hypertensive drugs with the survival or failure of dental implants. Only one study has been reported, which is associated with implant failure[0,6\%] There were not many articles in this field. The findings from this recent review demonstrate that more investigation is needed concerning hypertension and failure or survival of dental implants.
\end{abstract}

Keywords: Hypertension; Failure and survival of dental implants; Dental surgery

\section{Introduction}

A lot of prospective studies have provided evidence of the efficacy and effectiveness of the osseointegration technique in the treatment of completely and partially edentulous patients. It does not necessarily imply that Osseointegrated implant will remain in the bone successfully. There are secondary reasons for failure of Osseointegrated implants, with overload and infection most commonly cited [1]. Patients who want to receive implant prostheses often suffer from mental and physical stress during the surgical process. In many cases we can reduce physical stress under the appropriate anesthesia. Mental stress such as uneasiness and fear can cause blood pressure elevation $[2,3]$. Some investigators reported that there is a strong correlation between hypertension and dental implant surgery [4]. It has been reported that pain causes a large release of endogenous adrenaline. This explanation is supported by a case report of a 31-year old without hypertension who showed a sharp rise in average systolic and diastolic blood pressure [20,6 and 12,5 $\mathrm{mmHg}$ respectively] during painful dental implant treatment $[5,6]$.

A retrospective cohort study showed that antihypertensive medications may be associated with an increased survival rate of Osseointegrated implants [7]. The dental implant therapy in patients with systemic disorders should be designed, while taking into account long term complications that may arise. These kinds of complications are more frequent and severe than in a healthy patient. They can completely undermine the dental implant surgery. For example, in the case of patients with hypertension, the hypertensive medication that they receive has side effects as xerostomia, consecutive fungal infections of the mouth [candidiasis] Meanwhile, calcium blockers also used as anti-hypertensive medication, produce gingival hyperplasia, erythemia and ulcers both in the natural dentition and around dental implants [8].

\section{Objectives}

The aim of this study is to revise the current literature, in order to study the association of hypertension with the therapy of dental implants.

\section{Materials and Methods}

The blood pressure is considered to be affected by many factors including physical and psychological stress in dental implant treatment. The literature search was conducted by reviewers using medical databases [Medline via Pubmed, Embase] This review covered the time span between the years from 1992 to 2016. 


\section{Selection of studies}

The selected articles were screened by two reviewers according to the following exclusion and inclusion criteria.

\section{Exclusion criteria}

A. Studies in a language other than English.

B. Expert opinion papers.

\section{Inclusion criteria}

A. Studies evaluating blood pressure as a risk factor during dental implant treatment.
B. Prospective and retrospective cohort studies.

C. Studies with clinical examination of all included patients at the follow up visit.

\section{Result}

Anti-hypertensive drugs in general are beneficial for bone formation and remodeling and are associated with lower risk of bone fractures (Table 1). A retrospective cohort study included 1499 implants in 728 patients demonstrated that the patients using anti-hypertensive drugs lost only 2 implants (Table 2) [7]. Other study revealed that the histological appearance of bone derived from hypertensive patients was normal [9].

Table 1: Data collected from the articles that met the inclusion criteria.

\begin{tabular}{|c|c|c|c|}
\hline Author and Year & Type of Study & $\begin{array}{c}\text { Number of Im- } \\
\text { plants }\end{array}$ & Survival of Dental Implants \\
\hline $\begin{array}{c}\text { X Wu et al. 2016 } \\
\text { [7] }\end{array}$ & $\begin{array}{c}\text { Retrospective } \\
\text { Cohort study }\end{array}$ & 325 & $323[99,38 \%]$ \\
\hline Zhang Z et al. & Retrospective & 36 & 3 \\
\hline $\begin{array}{c}\text { Fabris et al. } 2017 \\
\text { [9] }\end{array}$ & Clinical study & 30 & $\begin{array}{c}\text { No numbers of implants. Regular alveolar bone with respect to bone } \\
\text { structure. }\end{array}$ \\
\hline
\end{tabular}

Table 2: Hypertension failure of dental implants.

\begin{tabular}{|c|c|c|c|}
\hline Author, Year & Sort of Study & Number of Dental Implants & Failure of Dental Implants \\
\hline X Wu et al. 2016 [7] & Retrospective cohort study & 325 & $2[0,6 \%]$ \\
\hline
\end{tabular}

\section{Discussion}

Patients demonstrate a physiological stress during dental implant surgery. Local anesthesia activates the adrenal cortex to produce cortisol. It is known that cortisol affects blood pressure during implant surgery. A clinical study showed that the blood pressure rising in patients who received dental implant surgery, caused no severe problems, because the patients in this study didn't have moderate or severe hypertension or cardiovascular disease [10].

During dental surgery an increased blood pressure places the patient at great risk of stroke, heart failure, myocardial infarction and renal failure. Around $30 \%$ of patients with hypertension remain undiagnosed and nearly $50 \%$ of patients on treatment are not controlled [11,12]. The hypothesis of higher risk of failures in patients with uncontrolled blood pressure is related to the possibility that the impaired blood supply and the consequent hypoxia may negatively affect the healing process of bone around implants [13]. Taguchi et al. [14] suggested sedation with midazolam before implant surgery, in order to better stabilize hemodynamic and reduce the stress. Dental implants are placed in the bone and do not have any effect on blood pressure, nor does the blood pressure have any effect on bone integration. However, blood pressure and medications taken to manage them create harmful situations for patients who have not properly addressed their condition with their treating dentists.
Local anesthesia drugs such as epinephrine have more intense effects on the heart. When combined with non-selective betablockers can result in rapid increases in blood pressure which is exactly what the anesthesia was supposed to help avoid pain, anxiety, and resulting higher blood pressure $[15,16]$. Only one study has been reported, which is associated with implant failure and hypertension [7]. The findings of the present study should be interpreted with great caution. Thus, the findings from this review should encourage the experts to investigate, in a prospective manner, the impact of hypertension on implants outcomes.

\section{Conclusion}

A. The impact of high blood pressure on long-term dental implants therapy remains in question.

In the future, more investigation is needed in order to clarify the role of blood pressure for dental implant treatment.

\section{References}

1. Jemt $\mathrm{T}$ (1993) Implant treatment in resorbed edentulous upper jaws. Clin Oral Impl Res 4(4): 187-194.

2. Coulthard P (2002) Should be checking blood pressure. Br Dent J 193 (5).

3. Greenwood M, Jowry RJ (2002) Blood pressure measuring equipment in the dental surgery: Use or ornament? Br Dent J 193 (5): 273-275.

4. Schwartz AD, Bar TY, Ilana E (2007) Effect of on information processing in the dental implant surgery setting. Clin Oral Impl Res 18(1): 9-12. 
5. Brand HS, Gortzaak RA, Palmer BC, Abraham RE, Abraham IL (1995) Cardiovascular and neuroendocrine responses during acute stress induced by different types of dental treatment. Int Dent J 45(1): 45-48.

6. Gortzak RA, Dosting J, Abraham IL (1992) Blood pressure response to routine restorative dental treatment without local anesthesia Continuous noninvasive blood pressure registration with a finger manometer. Oral Surg Oral Med Oral Pathol 73(6): 677-681.

7. Wu X, Abedalla K, Elmar H, Daniel NG, Nicolau B, et al. (2016) Antihypertensive medications and survival rate of osseointegrated dental implants: A cohort study. Clin Implant Dent Relat Res 18[6] 1171-1182.

8. Scully C, Hobkirk J, Dios PD (2007) Dental endosseous implants in the medically compromised patient. J Oral Rehabil 34[8]: 590-599.

9. Fabris ALS, Hassumi J, Freire AR, Faverani LP, Gruber R, et al. (2017) Morphometric and histological characterization of alveolar bone from hypertensive patients. Cl Impl Dent Relat Res 19[6]: 1106-1113.

10. Cairo F, Pagliaro V Nieri M (2008) Soft tissue management at implant sites. J Clin Period ontol 35(8Suppl): 163-167.
11. Little JW (2000) The impact on dentistry of recent advances in the management of hypertension. Oral Surg Oral Med Oral Path Radiol Endod 90(5): 591-599.

12. Jowett NI, Cabot LB (2000) Patients with cardiac disease: Considerations for the dental practitioner. Br Dent J 189(6): 297-302.

13. Moy PK, Medina D, Shetty V, Aghaloo TL (2005) Dental implant failure rates and associated risk factors. The Int J Oral Maxilofac Impl 20(4): 569-577.

14. Taguchi I, Fukuda K, Sekine H, Kakizawa T (2011) Intravenous sedation and haemodynamic changes during dental implant surgery. Int J Oral Maxillofac Impl 26(6): 1303-1308.

15. Chappuis V, Avila OG, Araujo MG, Monje A (2018) Medication-related dental implant failure: Systemic review and meta-analysis. Clin Oral Impl Res 29(suppl16): 55-68.

16. Silverstein LH, Koch JP Lefkove MD, et al. (1995) Nifedipine-induced gingival enlargement around dental implants: A clinical report. J Oral Implantol 21(2): 116-120. 